\title{
Simulation for Temperature Control of a Military Aircraft Cockpit to Avoid Pilot Thermal Stress
}

\author{
Janardhana Shetty ${ }^{1}$, Craig P Lawson ${ }^{2}$ and Amir Z Shahneh ${ }^{3}$
}

\begin{abstract}
During flying, military pilots are normally subjected to a number of stresses like mild hypoxia, high accelerations, vibrations and thermal discomfort. Among all of these, thermal stress is the most predominant factor while operating in highly tropical regions. Despite the use of aircraft's environmental control system, the temperature inside the cockpit may easily reach more than $10^{\circ} \mathrm{C}$ above ambient temperature and sometimes it may even exceed $45^{\circ} \mathrm{C}$. When these extreme temperatures are coupled with high relative humidity, causes for the degradation of both mental and physical performance of the pilots are present. This situation becomes severe, especially during low altitude and high speed operations due to aerodynamic heating of the external surfaces. Sometimes, at high altitude and low speed operations, the cockpit temperature falls and cold stress can pose a serious problem on the health of pilots. It is necessary to protect the pilots from high thermal stress to keep them under safe thermoregulatory limits and also help them perform an intended mission. This paper develops and deploys a basic method that can be used at an early design stage of any military aircraft to analyse the environmental control system's performance in avoiding pilot thermal stress. The method is also applicable to a design study for an enhanced environmental control system on an existing aircraft. Results present the effect of parameters including Mach number, altitude, ambient temperature, cockpit geometry, and solar radiation on cockpit thermal balance which have a direct impact on the thermal stress on pilots. A military aircraft with a cockpit volume of $1.5 \mathrm{~m}^{3}$ is considered for performing the thermal balance simulation studies. This paper also addresses the effects on engine bleed flow requirements, and corresponding air inlet temperatures to maintain the cockpit target Wet Bulb Globe Temperature of 28 ${ }^{\circ} \mathrm{C}$ as well as a pilot mean skin temperature target of $33{ }^{\circ} \mathrm{C}$. These are some of the thermal stress indicators proposed by different aero-medical authorities. These requirements are to be maintained if the physiological stress and impairment of performance of the pilots are to be avoided while operating in hot and humid environments.
\end{abstract}

\section{Keywords}

Environmental Control System, Simulation, Air-conditioning, pressurization, Wet bulb globe temperature, pilot mean skin temperature

\section{Acronyms}

$\mathrm{ACM}=$ Air cycle machine

ECS $=$ Environmental control system

FAA $=$ Federal aviation administration

HPWE = High pressure water extraction system

ISA $=$ International standard atmosphere

PHE $=$ Primary heat exchanger

$\mathrm{TCV}=$ Temperature control valve

MATLAB = Matrix laboratory

WBGT $=$ Wet bulb globe temperature

\footnotetext{
${ }^{1}$ Hindustan Aeronautics Limited, Aircraft R\&D center, Bangalore, India. E-mail : jhon82472@gmail.com

${ }^{2}$ School of Engineering, Cranfield University, United Kingdom. E-mail : c.p.lawson @ cranfield.ac.uk

${ }^{3}$ School of Engineering, Cranfield University, United Kingdom. E-mail : a.zareshahneh @ cranfield.ac.uk
} 


\section{Introduction}

Over past many years, there has been a radical technology changes in the field of military aviation. As technology grows, the operational requirements of a modern military aircraft have become more demanding. This will in turn necessitates the high level performance required by the pilots. All modern high performance military aircraft operate over a wide range of speeds and altitudes, and can consequently be subjected to a rapid temperature changes. Within a short time of take-off from sea level where the ambient temperature can be more than $45^{\circ} \mathrm{C}$, an aircraft can be flying at an altitude where ambient temperature is approximately $-60^{\circ} \mathrm{C}$ at $40,000 \mathrm{ft}$. This change in ambient temperatures at different altitudes makes it challenging for the pilots to perform effectively due to the presence of high thermal stress during operations.

During actual flying conditions the effectiveness of aircraft's cockpit air conditioning system is normally assessed by measuring the dry bulb temperature of the air, without considering the radiant temperature and humidity. The radiant temperature of the cockpit normally rises during low level flying due to kinetic heating of the airframe surfaces and also due to greenhouse effect. If the cockpit radiant temperature exceeds the pilot mean skin temperature of $33^{\circ} \mathrm{C}$ then the heat loss from the body cannot take place and consequently body starts gaining heat in such an environment. Meanwhile the humidity content of the cabin air starts increasing due to sweat evaporation of the pilots to keep the body temperature within the normal thermoregulatory requirements.

If the cockpit air-conditioning system is not effective enough in the removal of heat, the pilot's body reacts by sweating. If the sweating becomes ineffective, pilot's body temperature will rapidly rise beyond acceptable limits of flying. This necessitates assessing the efficacy of the cockpit air-conditioning system by measuring the wet bulb globe temperature (WBGT), or pilot's mean skin temperature.

The bootstrap air cycle machine is the most commonly used air refrigeration system in high performance military aircraft due to its proven record, simplicity and ease of maintenance. The main components include compressor, turbine, and heat exchanger. Both compressor and turbine are mounted on a common air bearing shaft. An additional fan may also be installed on a same shaft to induce more ram air during low level \& high speed operations. The energy produced by turbine during an expansion process is utilized to drive the compressor as well as a fan. In this paper a two-wheel bootstrap air cycle machine is considered for simulation studies in which both turbine and compressor are mounted on a common airbearing shaft without any fan.

\section{Description of ECS architecture of a military aircraft}

The system architecture of a state-of-the-art ECS with high pressure water extraction system is shown in Fig 1. This type of configuration is found on majority of the high performance military aircraft. In its operation the engine bleed air at a very high temperature and pressure goes through the pre-cooler and then splits into two airflows. One goes through the primary heat exchanger and is the main air source of the cooling sub-system, while the other goes through the temperature control valve and is the main air source of the heating sub-system.

The air of the cooling sub-system goes through the shut-off valve and splits into two flows. One goes through a by-pass valve and then joins the airflow of the heating sub-system, while the other is compressed through the bootstrap compressor. 
After compression, the air is again cooled down to near ambient temperature by the ram air charged cross flow secondary heat exchanger. This cooled air is then passed through a Re-heater where further drop in temperature of the air occurs.

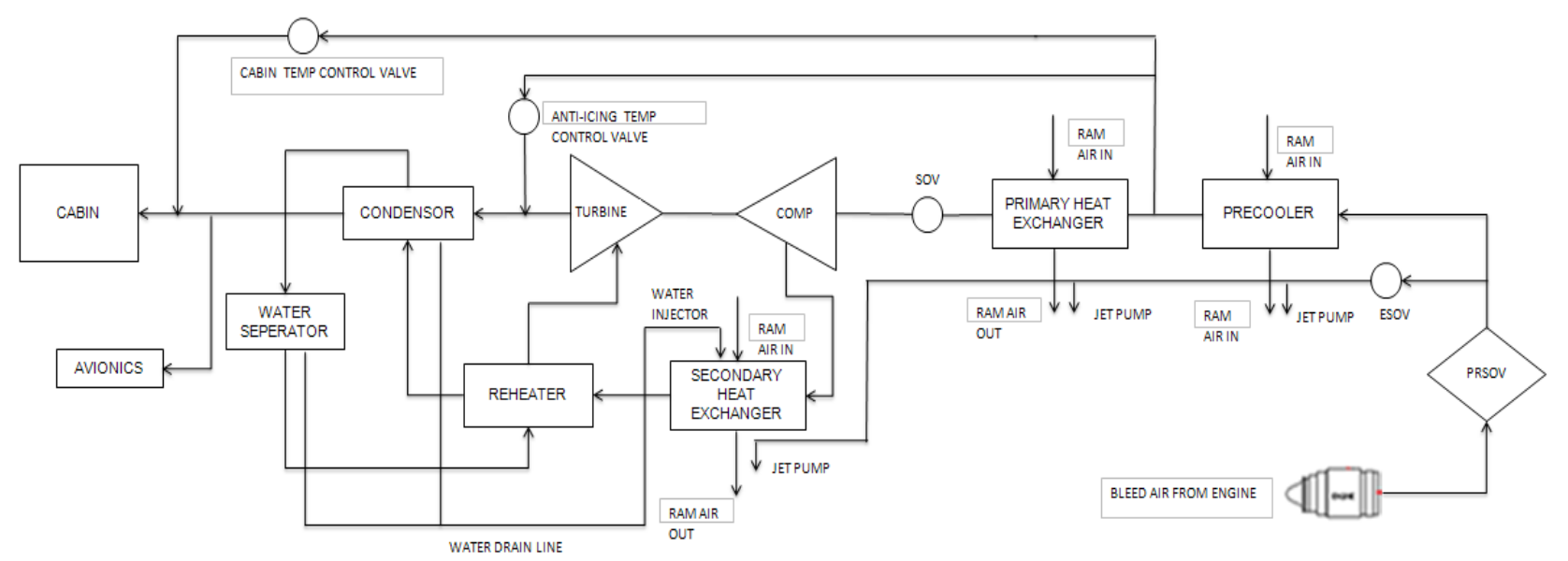

Fig 1. The system architecture of a strike aircraft ECS with high pressure water separation system

The rate of condensation in the Re-heater is quite low compared to the condenser and accounts for less than $30 \%$ of the total condensation achieved by the system. However the condensation function of the Re-heater is only a secondary one as the main purpose is to increase the temperature and energy level of the air before supplying it into the turbine. The air is then goes into the condenser and reaches the temperature where most of the water vapour present is condensed and becomes into liquid droplets. About $69 \%$ of the water vapour present in the air is removed at this stage. However some prior condensation takes place in the secondary heat exchanger and Re-heater before finally reaching the condenser. The air then goes into the high pressure water separator where $85 \%$ to $95 \%$ [1] of the water condensate is removed from the air through centrifugal action which imparts swirling motion to the air. The air then becomes dehumidified and contains about 1 to not more than 3 grains of total water vapour per kilogram of dry air.

The water droplets collected at the bottom of water separator is injected at the inlet of Secondary heat exchanger ram air duct to improve its effectiveness. Water spray nozzles are used for this purpose. This dehumidified air is then goes back to the re-heater where its temperature will increase while the temperature of the air coming from the secondary heat exchanger will decrease. The warm air with no moisture content is flown to the inlet of cooling pack turbine where it expands isentropically and cools down further. This cold air is then routed back to the condenser in which the temperature of the air will further come down before supplying it into the cockpit. During this process, the temperature of the air coming from regenerative heat exchanger drops as the expanded air will absorb the heat load from the moist air coming from the Reheater. The rise in temperature of the expanded air is equal to the amount of condensation removed from the incoming moist air and also the sensible cooling load corresponds to the temperature reduction imparted to the incoming air while at the condenser.

In order to achieve the desired cockpit temperature, the inlet temperature of the air being supplied into the cockpit required to be modulated. The hot air is tapped at a point downstream of primary heat exchanger for this purpose and is supplied via temperature control valves. The hot air is then mixed with cold air downstream of condenser in a mixing manifold till the 
required inlet temperature is maintained. The temperature control valves are fully automatic in operation and are modulated electronically in response to the selected cockpit temperature.

In high pressure water extraction system, the temperature at the downstream of cooling turbine may reach sub-zero temperatures to increase the cooling capacity of the system. This will pose an icing threat in ducts and condenser. In order to remove this ice formation, the temperature of the air is maintained above the freezing point temperature by supplying hot air from the anti-icing temperature control valve. The air required for avionics cooling is then taken from downstream of the condenser and is supplied via flow control valves. The dehumidified air for avionics cooling may be supplied at subzero temperatures at altitudes to meet the cooling demands.

\section{Modelling of ECS with a 2-wheel bootstrap air cycle machine}

The Environmental control system of a military aircraft is a quite complex thermodynamic system. It consists of many components, equipment and ducting for the processing of pressurized air bled from the engine compressor. Some of them include Pressure reducing and shut-off valve, Heat exchangers (air/air), Cold air unit, Condenser, Re-heater and Temperature control valves. These components/equipments have been modelled at system level by using appropriate governing/mathematical equations in MATLAB/Simulink workspace. Similarly the general atmospheric model with appropriate ISA deviation is considered for simulation study of cabin thermal balance by taking into account the various heat sources and other flight operating parameters.

\subsection{ISA atmospheric model}

An ISA atmospheric model is the first sub-system block created in MATLAB/Simulink workspace. This sub-system block plays a significant role during the simulation studies of cockpit thermal balance at different altitudes with varying flight operating conditions. The ISA model is used as a reference to compare the real atmospheric conditions and the corresponding aircraft performance. The atmospheric conditions will therefore be expressed as $I S \boldsymbol{A} \pm \Delta I S \boldsymbol{A}$ at a given flight altitude. In this paper a deviation of ISA $\pm 30^{\circ} \mathrm{C}$ is taken for building the simulation model.

\subsection{Model block for pressure reducing and shut-off valve (PRSOV)}

The main function of PRSOV is to regulate the bleed air pressure at the downstream of engine and also to shut-off the supply in case of over pressure detection. It is installed between the engine bleed point and a pre-cooler as shown in Fig 1. A control algorithm regulates the bleed air pressure at the downstream of PRSOV based on the pressure altitude. The following algorithm is built in the model block for simulation studies.

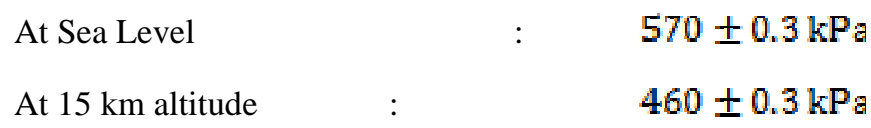


Where

$P_{\text {PESOV }}=$ Pressure at the downstream of PRSOV $(\mathrm{kPa})$

$P_{a} \quad=$ Aircraft pressure altitude $(\mathrm{kPa})$

\subsection{Air to air heat exchangers}

A heat exchanger is a device in which the two fluids exchanging thermal energy are separated by the heat transfer surfaces. The utilization of various types of airborne heat exchangers may be grouped based on their medium of heat exchange as

- Air to air heat exchangers (for example as used in air cycle refrigeration)

- $\quad$ Air to liquid (for example as used in vapour cycle refrigeration)

- $\quad$ Liquid to liquid (for example oil coolers utilizing fuel as a coolant)

Heat exchangers may also be grouped based on their operating characteristics as

- $\quad$ Direct transfer types

- Counter flow type

- Parallel flow type

- Cross flow type

However the air to air, cross flow type heat exchangers are most commonly used in aircraft air refrigeration applications. In this type of configuration both hot bleed air and cold ram air flow perpendicular to each other without mixing and are separated by heat transfer surfaces called fins. The heat exchangers considered in this model are cross flow, air to air and plate-fin type. The energy balance equation for the heat exchanger is represented as;

Heat lost by hot fluid (bleed air) = Heat gained by cold fluid (ram air)

$\dot{m}_{b} C_{P}\left(T_{E I}-T_{B O}\right)=\dot{m}_{r} C_{P}\left(T_{R O}-T_{R I}\right)$

Where

$\begin{array}{ll}\dot{m}_{b}= & \text { Mass flow rate of bleed air from engine }(\mathrm{kg} / \mathrm{sec}) \\ C_{D}= & \text { Ratio of specific heats at constant pressure }\left(\mathrm{kJ} / \mathrm{Kg}^{\circ} \mathrm{K}\right) \\ T_{E I} \text { and } T_{B O}= & \text { Inlet and outlet temperatures of bleed air }\left({ }^{\circ} \mathrm{K}\right) \\ \dot{m}_{r}= & \text { Mass flow rate of outside ram air }(\mathrm{kg} / \mathrm{sec}) \\ T_{E l}= & \text { Inlet Temperature of the ram air }\left({ }^{\circ} \mathrm{K}\right) \\ T_{E O}= & \text { Outlet Temperature of the ram air }\left({ }^{\circ} \mathrm{K}\right)\end{array}$


The effectiveness of the heat exchanger ( $\epsilon$ ) is represented as; [6]

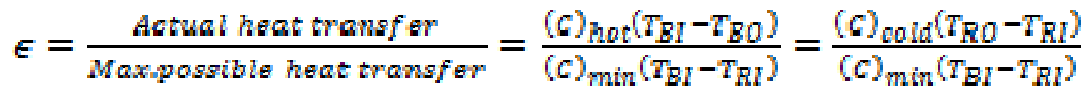

Where $(C)_{\min }$ is lower than $(C)_{\text {hot }}$ and $(C)_{\text {cole }}$ and $C$ is the heat capacity $(C=m * C p)$. By assuming that the difference between the $C_{P}$ of hot fluid and cold fluid is negligible, it implies that $\left(C_{p}\right)_{\text {hot }}=\left(C_{p}\right)_{\text {oord }}=C_{P}$. However for better heat transfer rate $C_{P(\text { blagdair })} \leqslant C_{p(\text { ramair })}$. Hence $(C)_{\text {min }}=(C)_{\text {ho: }}$

$\epsilon=\frac{T_{B I}-T_{B O}}{T_{B I}-T_{R I}}$

The above equation is rearranged as;

$T_{B O}=\varepsilon * T_{R I}-(\varepsilon-1) * T_{E I}$

The above equation is derived on the basis of ratio of two heat capacity rates

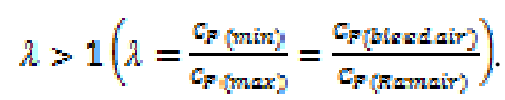
If $\lambda<1$, the numerator must be replaced by $T_{R 0}-T_{R I}$.

In order to obtain the actual pressure drop across each heat exchanger unit, it requires the detailed information on the geometry, materials, flow path and heat transfer coefficients of both the fluids [2]. The pressure drop depends on many other parameters including system pressure, flow rates, heat transfer media, materials roughness etc. The pressure drop curves w.r.t different mass flow rates are usually defined by the supplier. Despite, the pressure drop across the heat exchanger is considered to be isobaric theoretically, some pressure drop occurs due to change in dynamic and other parameters mentioned above. Due to non-availability of heat exchanger details, an average pressure drop across heat exchanger unit including pipeline losses is taken as $10 \mathrm{kPa}$ for the purpose of system level simulation studies.

The pressure at the outlet of each heat exchanger unit is taken as;

$P_{B O}=P_{B I}-10$

Where

$P_{B O} \quad=$ Bleed air pressure at the outlet of each heat exchanger $(\mathrm{kPa})$

$P_{D I} \quad=$ Bleed air pressure at the inlet of heat exchanger $(\mathrm{kPa})$ 


\subsection{Air cycle machine (Cold air unit)}

The air cycle machine works on the principle of an inverse Brayton cycle or inverse Joule cycle. It consists of a compressor, secondary heat exchanger, a turbine and a high pressure water separator. This loop removes the water condensate from air before supplying it into the cockpit and avionics cooling. In a two wheel bootstrap ACM the energy produced by the turbine during expansion process is utilized to drive the compressor at 40,000 rpm to $60,000 \mathrm{rpm}$ depending on the flow rates and pressure of the bleed air. [3]

The bleed air with reduced temperature (from the primary heat exchanger) enters the compressor of the air cycle machine where it undergoes isentropic compression causing both temperature and pressure to increase. Normally the downstream temperature of the compressor is restricted to a maximum of $250^{\circ} \mathrm{C}$ to $300^{\circ} \mathrm{C}$ for the air as an operating medium. By assuming that the compression process is isentropic and air is a perfect gas the governing equation for the outlet temperature of the compressor is taken as below.

$T_{C O}=T_{C I}\left[1+\frac{1}{n C}\left(\pi_{C} 0.286-1\right)\right]$

Where

$\mathbb{1}_{\mathrm{C}}=$ Isentropic efficiency of the centrifugal compressor,

$\mathrm{T}_{\mathrm{Cl}}=$ Compressor inlet temperature $(\mathrm{K})$

$\pi_{\mathrm{C}}=$ Compression ratio

Similarly the pressure at the outlet of compressor $(\mathrm{kPa})$ is given by;

$P_{C o}=P_{C l} * \pi_{C}$

Where

$\boldsymbol{P}_{\boldsymbol{C 1}}=$ Inlet pressure of the compressor $(\mathrm{kPa})$

The air after compression process passes through the Secondary heat exchanger where a further drop in temperature of the bleed air occurs.

\subsection{Re-heater}

The pressurized air with a reduced temperature from secondary heat exchanger flows to the inlet of Re-heater. The temperature of the air drops down further in the Re-heater before supplying to the condenser. Meanwhile the air coming from the water separator is heated up at the other side of Re-heater before supplying it to the inlet of turbine. The governing equations for the Re-heater are represented as below. 
Let

$T_{\text {RHICHp })}=$ Temperature of the air inlet at high pressure side $\left({ }^{\circ} \mathrm{K}\right)$

$T_{\text {RHO(Hp】 }}=$ Temperature of the air outlet at high pressure side $\left({ }^{\circ} \mathrm{K}\right)$

$T_{R H I(L p)}=$ Temperature of the air inlet at low pressure side (Water separator outlet) $\left({ }^{\circ} \mathrm{K}\right)$

$T_{R H O(L p)}=$ Temperature of the air outlet at low pressure side $\left({ }^{\circ} \mathrm{K}\right)$

$E_{R H} \quad=$ Effectiveness of the Re-heater

The drop in temperature across the high pressure water separator is assumed to be negligible for simulation studies. Hence the temperature of the air outlet at high pressure side of the Re-heater is represented as;

$T_{R H O(H p)}=\epsilon_{R H} * T_{R H I(L p)}-\left(\epsilon_{R H}-1\right) * T_{R H I(H p)}$

With energy balance equation, the temperature of the air outlet at the low pressure side of the Re-heater is taken as;

$T_{R H O(L p)}=\left(T_{R H I(H p)}-T_{R H O\langle H p)}\right)+T_{R H I L p)}$

The pressure drop across the Re-heater including pipeline losses is taken as;

$P_{\text {RHO }}=P_{\text {RHI }}-10 \quad \mathrm{kPa}$

\subsection{Condenser}

The air from Re-heater goes to the inlet of condenser and reaches the temperature where most of the water vapour present in the air is condensed and becomes into liquid droplets. Meanwhile, the air at the low pressure side of the condenser is heated up due to the exchange of heat energy from air at high pressure side of the condenser. The governing equation for condenser is represented as below.

Let

$T_{C D I C H y)}=$ Temperature of the air inlet at high pressure side $\left(\right.$ Re-heater outlet in $\left.{ }^{\circ} \mathrm{K}\right)$

$T_{C D O(H p)}=$ Temperature of the air outlet at high pressure side (Water separator inlet in ${ }^{\circ} \mathrm{K}$ )

$T_{C D I(L p)} \quad=$ Temperature of the air inlet at the low pressure side (Turbine outlet in ${ }^{\circ} \mathrm{K}$ )

$T_{C D O(L p)} \quad=$ Temperature of the air outlet at the low pressure side $\left(\right.$ Cockpit inlet in $\left.{ }^{\circ} \mathrm{K}\right)$

$E_{C D} \quad=$ Effectiveness of the condenser

Temperature of the air outlet at high pressure side of the condenser is represented as; 
$T_{C D O(H p)}=\epsilon_{C D} * T_{C D I(L p)}-\left(\epsilon_{C D}-1\right) * T_{C D I(H p)}$

With energy balance equation the temperature of the air outlet at the low pressure side is taken as;

$T_{C D O(L p)}=\left(T_{C D I(H p)}-T_{C D O(H p)}\right)+T_{C D I(L p)}$

From Fig 1 it may be noted that, $T_{C D I(H p)}=T_{R H O(H p)}$ and $T_{C D O(H p)}=T_{R H I(\mathrm{Lp})}$

The pressure loss across the condenser with pipeline lossess is taken as

$P_{C D Q}=P_{C D I}-10 \quad k P a$

Where $P_{C D I}$ is the low pressure side of the condenser $(\mathrm{kPa})$

\subsection{Cooling Pack Turbine}

The warm air from the Re-heater enters at the inlet of cooling pack turbine. The air expands isentropically bringing down both pressure and temperature. The temperature of the air after expansion may reach sub-zero level reaching up to $-30^{\circ} \mathrm{C}$ to $35^{\circ} \mathrm{C}$. By assuming that expansion processes is isentropic and air is a perfect gas, the temperature at the downstream of turbine is obtained by a governing equation given below.

$$
T_{T O}=T_{T I}\left[1-\eta_{z}\left(1-\pi_{z}^{-0.286)}\right]\right.
$$

Where

$\pi_{t}=$ Turbine expansion ratio $=\frac{P_{I N}}{P_{O U T}}$,

$P_{L N}=$ pressure at inlet of turbine $(\mathrm{kPa})$

$T_{T I}=$ Turbine inlet temperature $(\mathrm{K})$

$\eta_{t}=$ Isentropic efficiecy of the turbine.

From schematic diagram shown at Fig 1, it may be noted that $T_{T I}=T_{R H O(L p)}$.

Similarly the pressure $\left(P_{\text {ouT }}\right)$ at the downstream of turbine is given by;

$$
P_{\text {OUT }}=\frac{P_{I N}}{\pi_{t}}
$$


The model block for Re-heater, Condenser and a Cooling pack turbine is built in the MATLAB/Simulink workspace as shown in Fig 2.

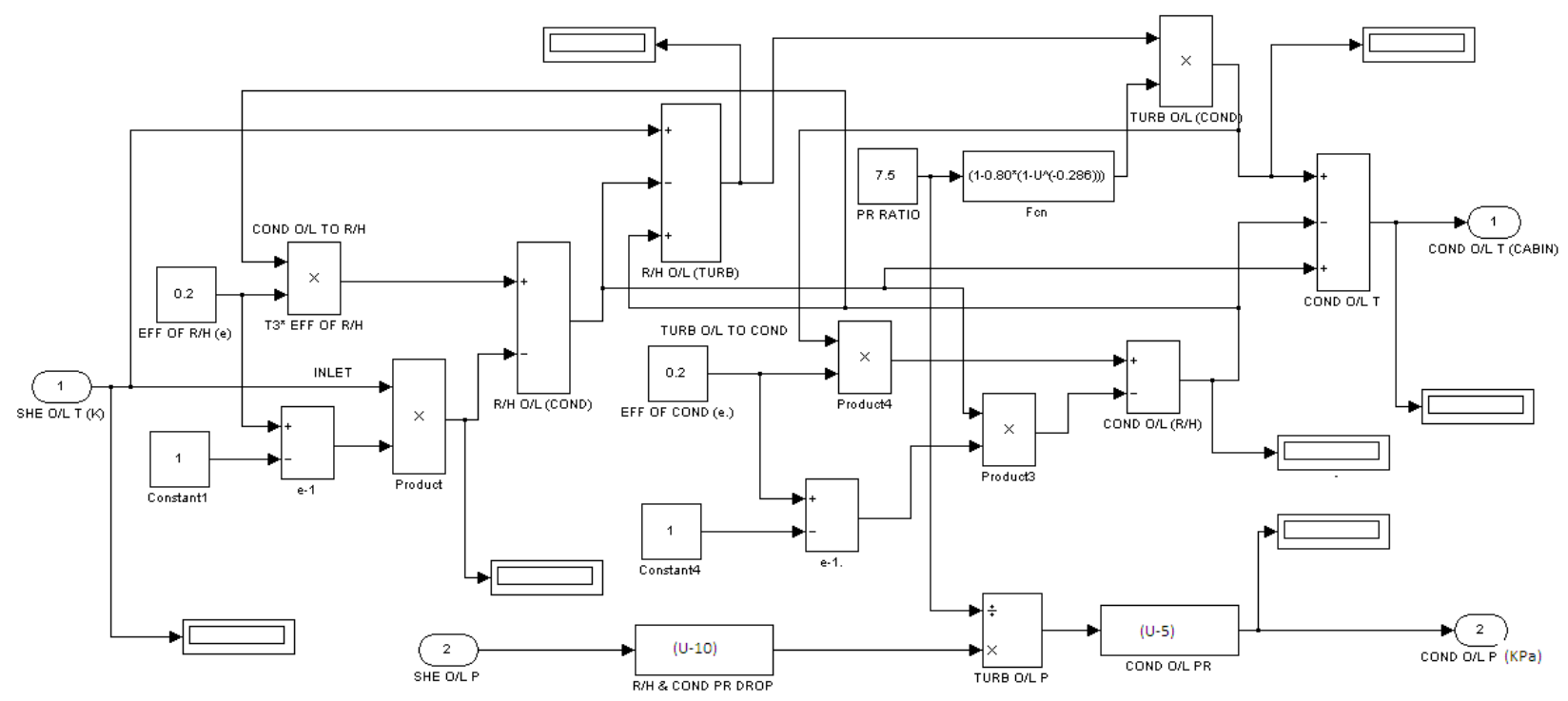

Fig 2. The Model block for re-heater, condenser and a cooling pack turbine

\section{Temperature control valve (Trim air valve)}

During high altitude flights the amount of heat loss from cockpit is predominantly high due to low ambient temperatures. In order to compensate this heat loss and also to maintain the desired cockpit temperature it is necessary to supply the air at higher temperature into the cockpit. This is achieved by the use of temperature control valves. The temperature of the air at the downstream of low pressure side of the condenser is limited to $4^{\circ} \mathrm{C}$ to avoid cold draft in the ducts. The model is built in such a way that, if temperature of the air goes below this point, TCV is modulated to allow $10 \%$ of the hot air from downstream of the primary heat exchanger and mixes with cold air of the condenser outlet. This modulation will continue till the desired cabin temperature is achieved. By assuming that enthalpy of the incoming air is equal to the enthalpy of the outgoing air a control algorithm can be written in the model as shown in figure 3 .

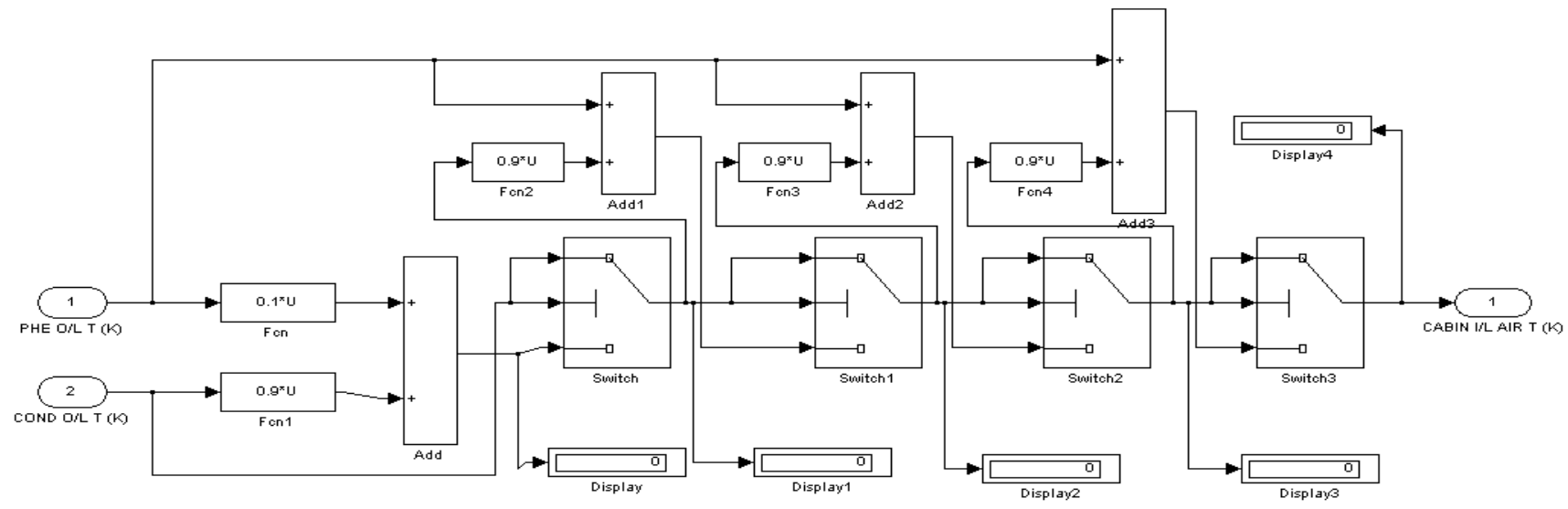

Fig 3. The Model Block for a Temperature Control Valve 


$$
\begin{aligned}
& \bar{m}_{C A B(I / L)} * T_{C A B(L / L)}=\left[\left(X * \dot{m}_{F H E(O / L)}\right) * T_{P H E(O / L)}\right]+\left[\left(Y * m_{C O N D(O / L)}\right) * T_{C O N D C O / L)}\right] \\
& \bar{m}_{C A B(L / L)} * T_{C A B(I / L)}=\left[\left(0.1 * m_{C A B(I / L)}\right) * T_{P H E(O / L)}\right]+\left[\left(0.9 * m_{C A B(I / L)}\right) * T_{C O N D C O / L)}\right] \\
& T_{C A B(1 / L)}=\left[\left(0.1 * m_{C A E(I / L)}\right) * T_{P H E(O / L)}\right]+\left[\left(0.9 * m_{C A E(I / L)}\right) * T_{C O N D(O / L)}\right] / m_{C A B(I / L)} \\
& T_{C A B(I / L)}=\left(0.1 * T_{P H E(O / L)}\right)+\left(0.9 * T_{C O N D(O / L}\right)
\end{aligned}
$$

\section{Cockpit pressurization system}

The need to pressurize the aircraft cockpit originates from the basic requirement to isolate the pilots from reduced atmospheric pressures encountered at high altitudes. This is necessary to protect the occupants from dangers and discomfort arising from low oxygen content and also from the effects of extremely reduced pressure on the body. The minimum $\mathrm{PO}_{2}$ allowed in aircraft cockpit at the maximum allowed cabin pressure altitude of $2440 \mathrm{~m}$ (8000ft) is $74 \%$ of the sea level value as specified in FAA Sec 25.841. This would be required to protect the occupants from the effects of onset of hypoxia [4]. In order to build the model, the following pressurization schedule is chosen. This type of schedule is normally found in many of the recently developed high performance military aircraft. [5]

From Sea Level to $8000 \mathrm{ft}$. Cockpit pressure $=$ Atmospheric pressure

From $8000 \mathrm{ft}$. to $23000 \mathrm{ft}$. Cockpit pressure $=75.2 \mathrm{kPa}$ (Isobaric range)

From $23000 \mathrm{ft}$. to ceiling altitude Cockpit pressure $=$ Atmospheric pressure $+34.5 \mathrm{kPa}$ (Constant differential pressure)

\section{Density of cockpit air}

In order to simulate the cockpit for thermal balance, it is necessary to find out the density of air inside the cockpit. The following equation is used to build the model block.

Density of cabin air $\left(\rho_{\text {Cabinair }}\right)=\frac{P_{C}}{{ }^{*} T_{\text {Avg }}}$

Where

$P_{C}=$ Cockpit pressure $(\mathrm{Pa})$,

$T_{\text {Avg }}=$ Cockpit average temperature (K)

$R=$ Gas constant $\left(\mathrm{m}^{2} /{ }^{\circ} \mathrm{K} \sec ^{2}\right)$

\section{Cockpit Thermal Balance}

A precise analysis of different heat loads is the first process involved in cockpit thermal balance study for any military aircraft. It requires a detailed knowledge about cockpit heat transfer mechanisms, cockpit structural geometry and data on flight operating conditions. The cockpit thermal balance study is required to validate the requirement of engine bleed flow rates at different temperatures for varying heat loads. This study is also required to analyse and validate the temperature 
stabilization time during cockpit cabin pull up and pull down cases. The stabilization criteria are to reach the desired temperature, and then remain within 2 degrees Kelvin of this value.

The cockpit thermal balance is given by the following equation.

$\Sigma_{Q=i}^{Q=n} Q+m_{\text {Cos inlet })} * C_{p} *\left(T_{\text {Cab in }}-T_{\text {Cabout }}\right)=m_{\text {themal }} * C * \frac{d T_{\text {Avg }}}{d t}$

Where

$\sum_{Q=i}^{Q=n} Q=$ Total cabin heat loads (Watts)

$m_{(\text {cabinlst })}=$ Mass flow rate at the inlet of the cabin $(\mathrm{kg} / \mathrm{sec})$

$C_{p}=S p$. heat capacity of the inlet air at constant pressure $\left(V / K g .{ }^{\circ} \mathrm{K}\right)$

$T_{\text {eabin }}=$ Temperature of the cabin inlet air $(K)$

$T_{\text {Eabout }}=$ Temperature of the cabin discharge air $(K)$

The term $m_{\text {thommal }} * \mathrm{C}$ can be defined as below

$m_{\text {themmal }} * C=m_{\text {cabair }} * C_{V}+m_{\text {cabsqpts }} * C_{p(c a b a q t s)}$

$\dot{m}_{\text {cabair }}=$ Mass of the air inside the cabin $(\mathrm{Kg})$

$C_{V}=$ Specific heat capacity of the cabin air at constant volume $\left(J / \mathrm{Kg}^{\circ} \mathrm{K}\right)$

$m_{\text {cabegptg }}=$ Mass of the cabin structural panels and equipment $(\mathrm{kg})$

$C_{p(c e b e q p r)}=S p$. heat capacity of the cabin Al.structural panels \& eqpts $\left(\mathrm{K} / \mathrm{Kg} \cdot{ }^{\circ} \mathrm{K}\right)$

To carry out the simulation studies for cockpit thermal balance the basic data required are taken as listed in Table 1.

Table 1. Basic data for cockpit thermal balance simulation

\begin{tabular}{|lll|}
\hline Details & Values & Units \\
Volume of the cockpit $(V)$ & 1.5 & $\mathrm{~m}^{3}$ \\
$C_{p}$ of cockpit inlet air & 1005 & $\mathrm{~J} / \mathrm{kg} \cdot \mathrm{K}$ \\
$C_{V}$ of cockpit inlet air & 720 & $\mathrm{~J} / \mathrm{kg} \cdot \mathrm{K}$ \\
\hline
\end{tabular}




\begin{tabular}{|lll|}
\hline$C_{p}$ of cockpit structural panels \& eqpt & 875 & $\mathrm{~J} / \mathrm{kg} . \mathrm{K}$ \\
$m_{c a b \text { «qpts }}$ & 20 & $\mathrm{~kg}$ \\
\hline
\end{tabular}

\section{Cockpit heat loads}

The aerodynamic heating of airframe surfaces and solar radiation through transparencies are the major heat sources into the cockpit. However the intensity of aerodynamic, bay and solar heating may vary depending upon speed, ambient temperatures and altitude of flying. The metabolic heat load mainly depends on the degree of pilot's activity level. Electrical \& avionics heat loads may vary depending upon the mission and operational requirements of the equipment.

The details of various cockpit heat loads taken for simulation studies are given below.

- Metabolic heat load $\left(Q_{\text {Pilot }}\right)=400$ Watts (For single pilot)

- Avionics heat load(Q $\left.Q_{\text {Avionice }}\right)=1100$ Watts $[6]$

- Radiative heat transfer through transparencies

$Q_{\text {Rad }}=A_{\text {Rad }} \tau \cdot Q_{a i}$

Where

$A_{\text {Rad }}=$ Transparency areas (Windscreen and Canopy) exposed to solar radiation $\left(\mathrm{m}^{2}\right)$

$A_{\text {Rad }}=(0.7 * 1.5+0.5 * 0.4)=1.25 \mathrm{~m}^{2}$

$\tau=$ Transmittance of the transparency area $=0.83[7]$

$Q_{g i}=$ Incident solar radiation $\left(\mathrm{W} / \mathrm{m}^{2}\right)$

The value of $Q_{\pi i}$ is taken as $1200 \mathrm{~W} / \mathrm{m}^{2}$ at sea level and $1600 \mathrm{~W} / \mathrm{m}^{2}$ at high altitudes in this simulation study [8].

The data which are considered for cockpit heat loads analysis are listed in Table 2.

Table 2. Data for cabin heat loads analysis

\begin{tabular}{|l|l|}
\hline \multicolumn{1}{|c|}{ Parameters } & \multicolumn{1}{c|}{ Values } \\
\hline Altitude & Sea Level \\
\hline Outside ambient temperature (OAT) & $45^{\circ} \mathrm{C}\left(318.15^{\circ} \mathrm{K}\right)$ \\
\hline Weather condition & Cloudless sky \\
\hline Speed of the aircraft (Mach) & 0.6 \\
\hline Sea Level pressure & $1.013^{*} 10^{5} \mathrm{~N} / \mathrm{m}^{2}$ \\
\hline Absolute humidity of the cabin air & $0.008 \mathrm{~kg} / \mathrm{kg}$ of $\mathrm{d}_{\mathrm{a}}$ \\
\hline Thermal conductivity of skin material & $170 \mathrm{~W} / \mathrm{m}^{\circ} \mathrm{k}($ Al. alloy) \\
\hline Thermal conductivity of insulating material & $0.048 \mathrm{~W} / \mathrm{m}^{\circ} \mathrm{k}$ (Fiberglass) \\
\hline
\end{tabular}




\begin{tabular}{|l|l|}
\hline Thickness of the insulating material & $0.001 \mathrm{~m}$ \\
\hline Thickness of the aircraft skin material & $0.0015 \mathrm{~m}$ \\
\hline Thickness of the windscreen material & $0.018 \mathrm{~m}$ \\
\hline Thickness of the canopy material & $0.007 \mathrm{~m}$ \\
\hline Wall conductivity of the transparency material (Perspex) & $11.6 \mathrm{~W} / \mathrm{m}^{2}{ }^{\circ} \mathrm{K}$ \\
\hline
\end{tabular}

The convective heat transfer through non-insulated structural projections with fin efficiency $\left(\mathrm{n}_{F}\right)$ is given by;

$Q_{C o n}=U_{C o n} A_{C o n}\left(T_{r a m}-T_{A v g}\right) * \eta_{E}$

The aerodynamic heating through cockpit side walls, pressure bulkheads, floor and transparency areas are taken as below. The convective heat transfer $(Q)$ is given by the equation;

$Q=U * A\left(T_{\text {ram }}-T_{\text {Avg }}\right)$

Where $\boldsymbol{U}=$ Heat transfer co-efficient $\left(\mathrm{W} / \mathrm{m}^{2}{ }^{\circ} \mathrm{K}\right), \boldsymbol{A}=$ Surface area $\left(\mathrm{m}^{2}\right), \boldsymbol{T}_{\mathrm{ram}}=$ Ram air temperature $\left({ }^{\circ} \mathrm{K}\right)$ and $T_{\text {Avg }}=$ Average temperature of the cockpit air $\left({ }^{\circ} \mathrm{K}\right)$

The value of $\boldsymbol{U} * A$ for each of the cockpit walls including transparencies is taken as below.

$$
\begin{array}{ll}
(U * A)_{\text {Side walls }} & =5.715 * 1.86=10.65 \mathrm{~W} /{ }^{\circ} \mathrm{K} \\
(U * A)_{\text {Bulkhouds }} & =3.455 *[(0.9 *(0.3+0.65))]=3.0 \mathrm{~W} /{ }^{\circ} \mathrm{K} \\
(U * A)_{\text {Botromwalls }} & =3.455 * 0.93=3.22 \mathrm{~W} /{ }^{\circ} \mathrm{K} \\
(U * A)_{\text {Transpargcy }} & =7.47 *(1.5+0.4)=14.20 \mathrm{~W} /{ }^{\circ} \mathrm{K}
\end{array}
$$

$\sum U A=31.2 W /{ }^{\circ} K$

Therefore the total convective heat transfer (at 0.6 Mach at sea level) through above aerodynamic surfaces is given by;

$\Sigma Q=31.2 *\left(T_{\text {ram }}-T_{\text {Avg }}\right)$

$T_{\text {Avg }}=$ Cockpit average temperature $\left({ }^{\circ} \mathrm{K}\right)$

$T_{\text {Avg }}=0.5 *\left(T_{\text {in }}+T_{\text {out }}\right)$

Research studies have shown that the air flow requirements for pilot thermal comfort are also very dependent on the cockpit air distribution system. As suggested by research study [9] that with an optimum cockpit air distribution system a mean temperature of the air at the vicinity of the pilot is given by; 


$$
T_{m}=0.25 * T_{\text {in }}+0.75 * T_{\text {out }}
$$

$T_{m}=$ Cockpit mean temperature at the vicinity of the pilot $\left({ }^{\circ} \mathrm{K}\right)$

$T_{\text {in }} \& T_{\text {out }}=$ Cockpit inlet and outlet temperatures $\left({ }^{\circ} \mathrm{K}\right)$

The combined model block for cockpit heat loads and cockpit thermal balance analysis is shown in Fig 4.

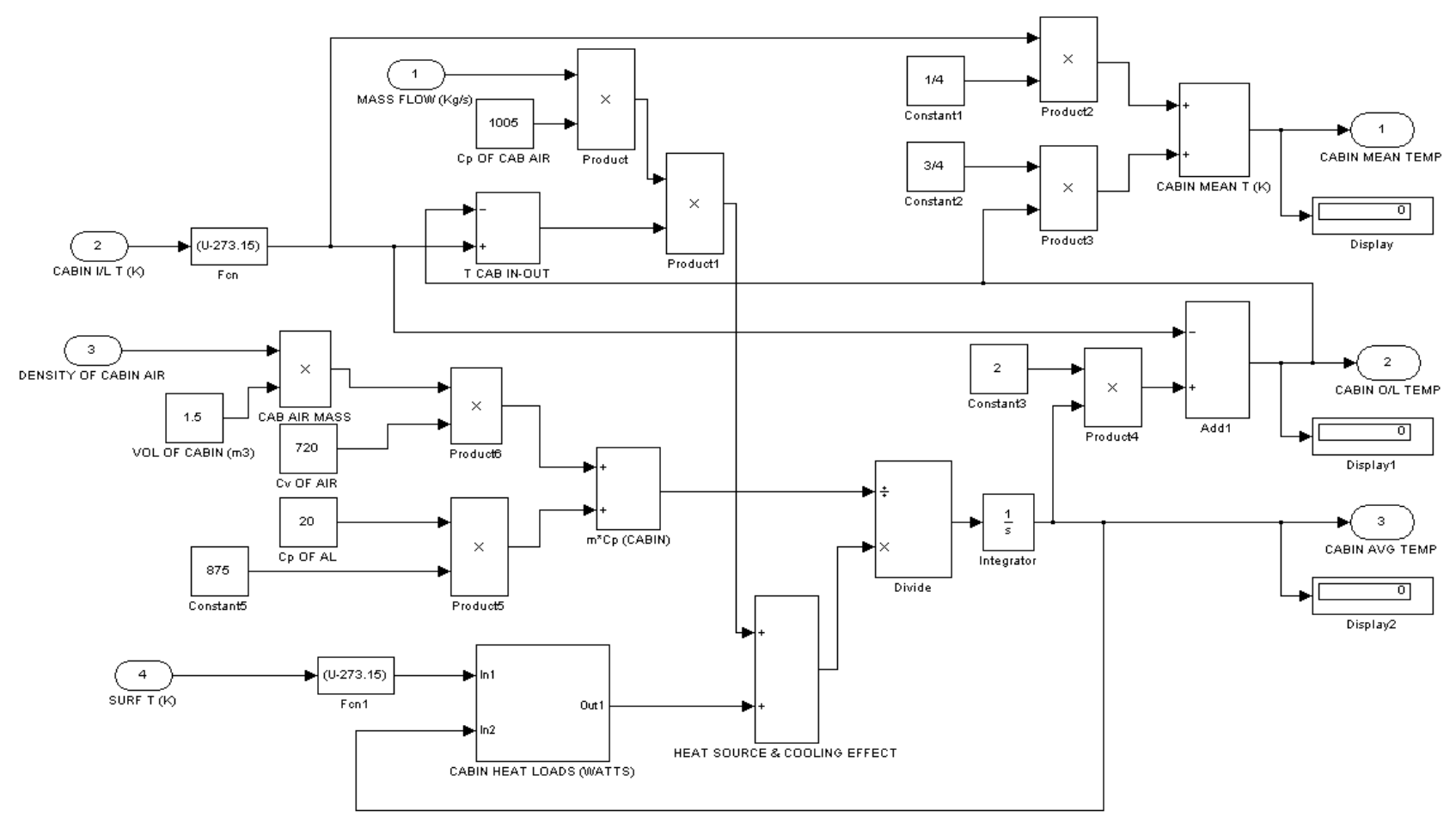

Fig.4 The combined model block for cockpit heat loads \& cockpit thermal balance

\section{Results and discussion}

The cockpit thermal balance simulations are carried out for various flight operating conditions to analyse the net effect on pilot thermal stress resulting from cockpit temperatures and pressures encountered. Meanwhile the corresponding effect on engine bleed flow rates and inlet temperature requirements to avoid the thermal stress on pilot are also analysed.

\subsection{Maximum Cockpit Cooling Analysis}

Based on a typical flight envelope of a modern high performance military aircraft, the following parameters are set for the maximum cockpit cooling case analysis. The maximum speed of the aircraft is 0.9 Mach at sea level, ambient temperature $45^{\circ} \mathrm{C}$, cockpit thermal mass of $20 \mathrm{~kg}$ and a solar radiation intensity of $1200 \mathrm{~W} / \mathrm{m}^{2}$. 


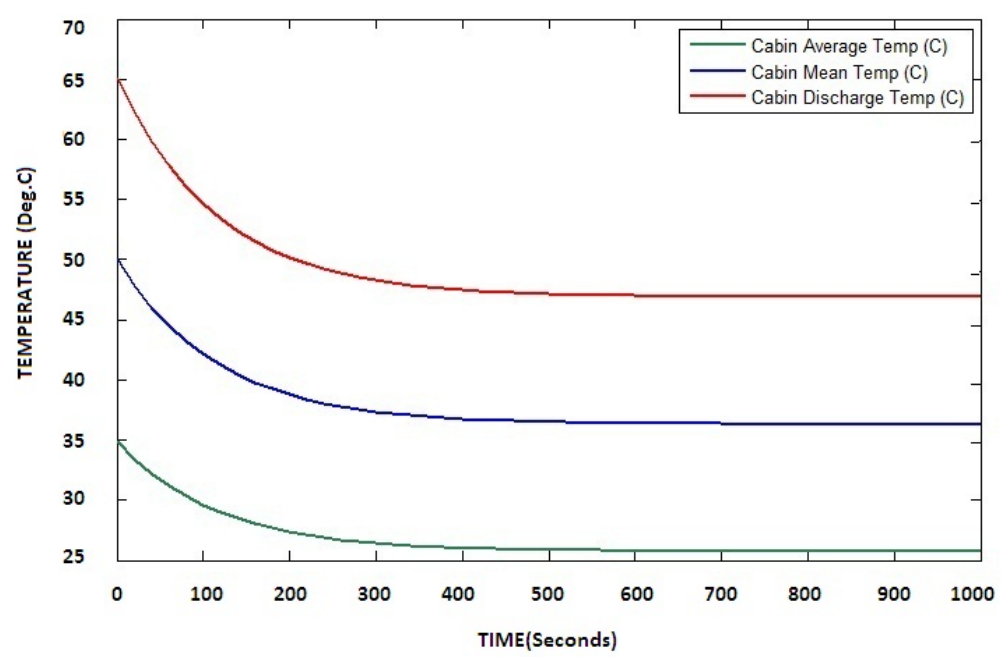

Fig 5. The mass flow rate for a maximum cockpit cooling case analysis

It is shown that a mass flow rate of $0.15 \mathrm{~kg} / \mathrm{sec}$ is required to meet the requirement of maximum cockpit cooling scenario with an air inlet temperature of $9.6^{\circ} \mathrm{C}$ at the downstream of $\mathrm{TCV}$. This is the minimum mass flow rate requirement to ensure a maximum cockpit WBGT of $28^{\circ} \mathrm{C}$ and more. However higher mass flow rates are required to further bring down the WBGT lesser than $28^{\circ} \mathrm{C}$ to avoid an excessive heat stress on the pilots. The time required for the stabilization of cockpit temperatures is less than 7 minutes as shown in Fig 5. The equivalent cockpit mean and average temperatures are $37^{\circ} \mathrm{C}$ and $26^{\circ} \mathrm{C}$ respectively for the corresponding cockpit WBGT of $28^{\circ} \mathrm{C}$. This limit ensures a minimum acceptable thermal comfort level; anything beyond this limit can cause a degradation of mental performance of the pilots. [7]

\subsection{Maximum Cockpit Heating Analysis}

The following parameters are set for the maximum cockpit heating case analysis. The speed of the aircraft is 0.6 Mach at $15 \mathrm{~km}$ altitude, the equivalent ground ambient temperature is $30^{\circ} \mathrm{C}$, the cockpit thermal mass of $20 \mathrm{~kg}$ and the solar radiation intensity is $1600 \mathrm{~W} / \mathrm{m}^{2}$. It is shown that a mass flow rate of $0.04 \mathrm{~kg} / \mathrm{sec}$ is required to meet the maximum cockpit heating scenario with an air inlet temperature of $15^{\circ} \mathrm{C}$ at the downstream of temperature control valve.

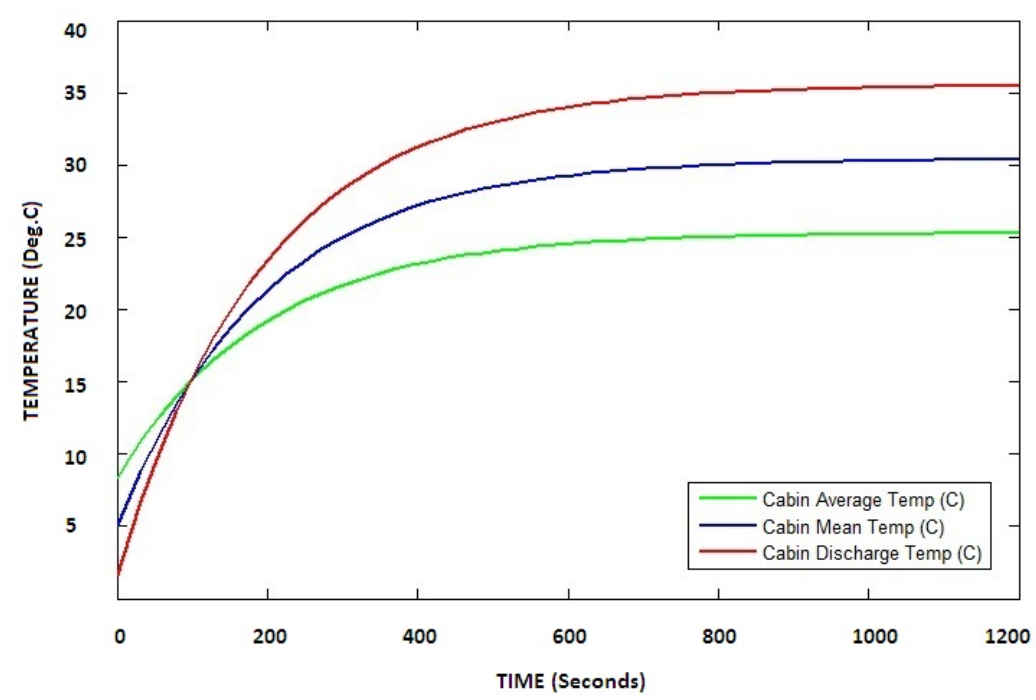

Fig 6. The mass flow rate for a maximum cockpit heating case analysis 
The time required for the stabilization of cockpit temperatures is less than 10 minutes, as shown in Fig 6. It is to be noted that this is the minimum mass flow rate requirement to achieve a maximum cockpit WBGT of $28^{\circ} \mathrm{C}$ for the specified cockpit structure during heating case scenario. However, higher mass flow rates are required to further bring down the cockpit WBGT below $28^{\circ} \mathrm{C}$, to enhance the thermal comfort level by avoiding an excessive heat stress on the pilots.

\subsection{Effect of Mach Numbers Analysis on cockpit temperatures}

This study is carried out with the parameters defined in the cockpit cooling case analysis at different Mach numbers with a constant mass flow rate of $0.092 \mathrm{~kg} / \mathrm{sec}$ into the cockpit. This mass flow rate is chosen to achieve a WBGT of $28^{\circ} \mathrm{C}$ at 0.3 Mach. It is shown that the effect of aerodynamic heating of the airframe surfaces is significant on cockpit thermal balance at low altitude and high speed flight cases. As the speed of the aircraft increases the surface temperatures also increases inducing more heat flow into the cockpit as shown in fig 7.

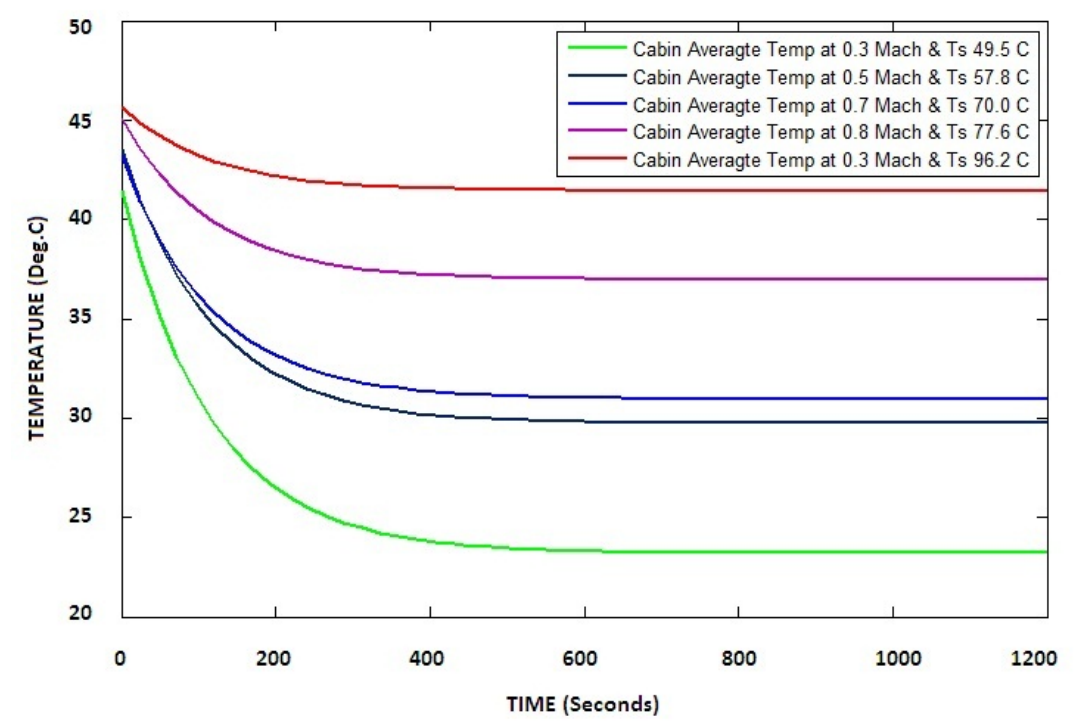

Fig 7. Effect of Mach numbers on cockpit temperatures

This additional heat flow into the cockpit through structural surfaces and transparency areas increases the cockpit average temperature dramatically. This high cockpit temperature can cause a degradation of both mental and physical performance of the pilots. However, this necessitates higher mass flow requirements to avoid excessive heat stress on the pilots.

\subsection{Effect of Solar Radiation Analysis on Cockpit Temperatures}

The effect of solar radiation is predominant at high altitude flight cases. In order to study this effect of solar radiation on cockpit temperatures and mass flow requirements, simulations are carried out at two different altitudes i.e. one at sea level and another at $9 \mathrm{~km}$. 


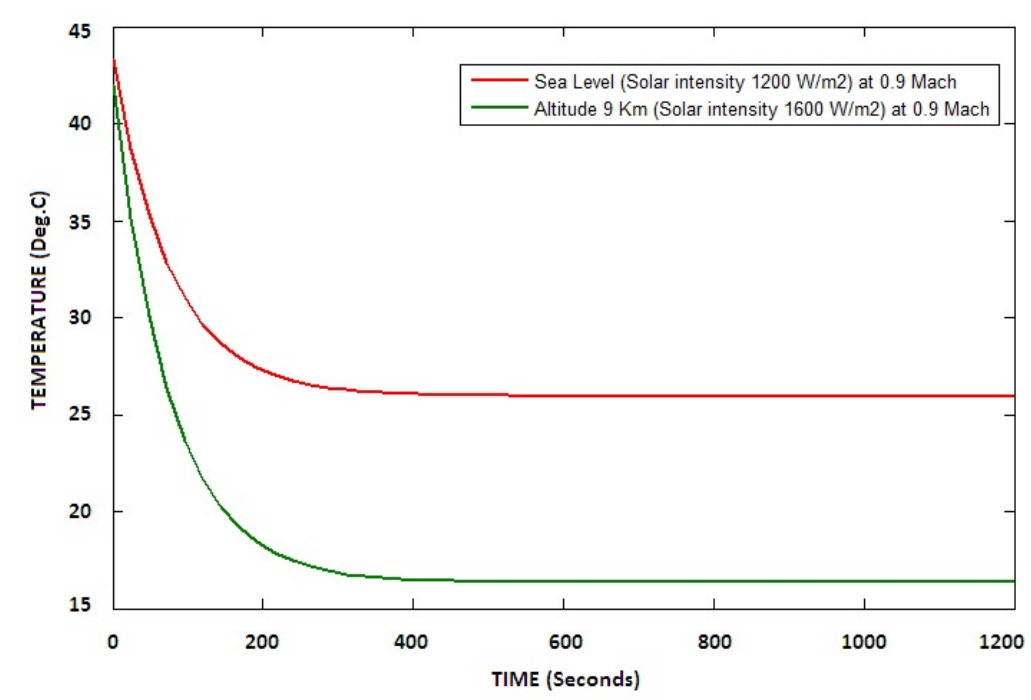

Fig 8. Effect of solar radiation intensity on cockpit temperatures

The parameters set for this simulation study include ambient temperature of $45^{\circ} \mathrm{C}$, the cockpit thermal mass of $20 \mathrm{~kg}$, the solar radiation intensity is $1200 \mathrm{~W} / \mathrm{m}^{2}$ at sea level and $1600 \mathrm{~W} / \mathrm{m}^{2}$ at $9 \mathrm{~km}$ altitude. Also a constant mass flow rate of 0.15 $\mathrm{kg} / \mathrm{sec}$ is supplied in both the cases to study the net effect of solar radiation. This mass flow rate is chosen to achieve a WBGT of $28^{\circ} \mathrm{C}$ in the high altitude, 0.9 Mach case. From Fig 8 it can be seen that for a constant mass flow rate, the cockpit average temperatures are found to be $26^{\circ} \mathrm{C}$ at sea level and $16.5^{\circ} \mathrm{C}$ at an altitude of $9 \mathrm{~km}$ respectively. It implies that for the same amount of mass flow rate the net cooling effect of the cockpit and heat stress on pilots are better at higher altitudes.

\subsection{Effect of Cockpit Thermal Mass on Cockpit Temperatures}

The parameters set for the cockpit cooling case analysis are considered to study the net effect of thermal mass on the cockpit average temperatures at a constant mass flow rate of $0.15 \mathrm{~kg} / \mathrm{sec}$. This mass flow rate is chosen to achieve a WBGT of $28^{\circ} \mathrm{C}$. The mass of the air supplied into the cockpit is computed by taking the density of air at sea level as $1.225 \mathrm{~kg} / \mathrm{m}^{3}$ and a cockpit volume of $1.5 \mathrm{~m}^{3}$. From Fig 9 it can be seen that the time required for the stabilization of cockpit average temperatures in both the cases is substantially longer.

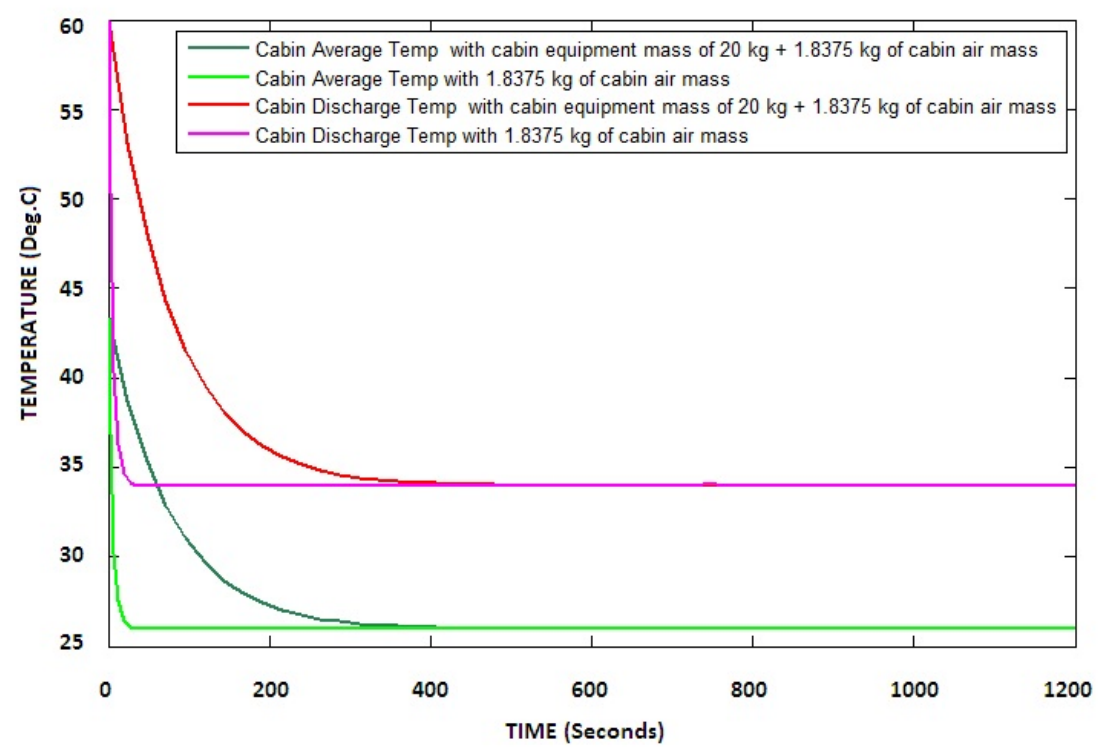


Fig 9. Effect of cockpit thermal mass on cockpit average temperatures

The time taken with the consideration of cockpit thermal mass of $20 \mathrm{~kg}$ is approximately 6 minutes, whereas the time taken without the consideration of cockpit thermal mass is less than one minute. As expected, this shows that the lower the thermal mass, the less the time taken for stabilization of the cockpit temperatures.

\subsection{Effect of Cockpit Geometry on Cockpit Average Temperature}

In order to study the net effect on convective heat transfer due to change in cockpit geometries, the parameters set for the cockpit cooling case analysis have been considered. The main structural surfaces involved in the convective heat transfer process include cockpit side walls, floors, pressure bulkheads and transparency areas. By applying the convective heat transfer mechanism for the above surface areas, the effect on heat transfer into the cockpit is analysed. From fig 10, it can be noted that as the product of convective heat transfer coefficient and surface area increases, the cockpit average

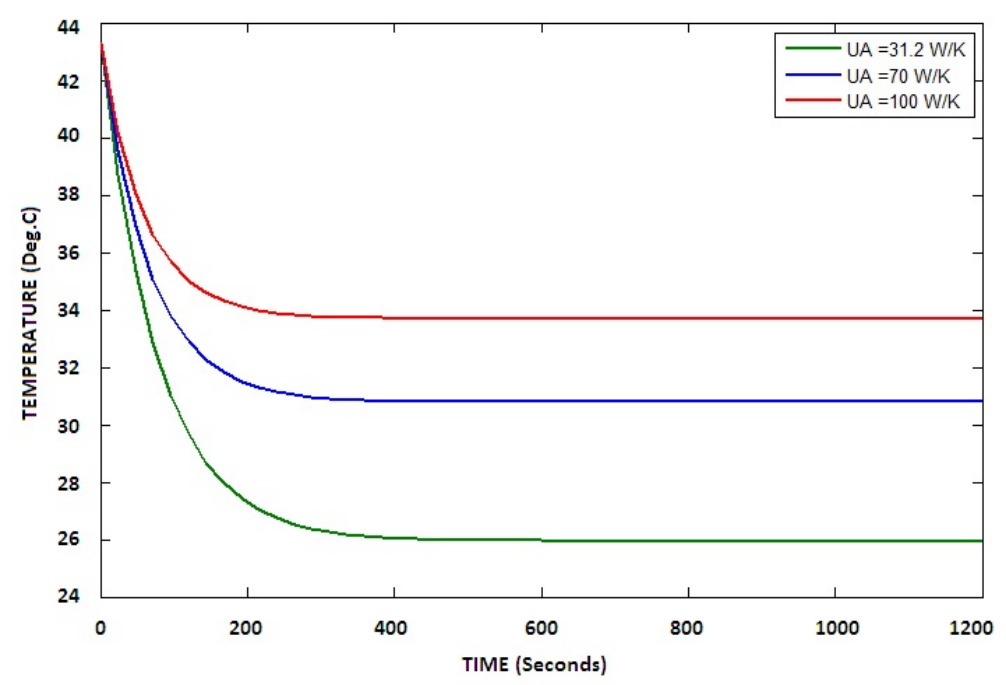
temperature also increases.

Fig 10. Effect of cockpit geometry on cockpit average temperature

In other words, as the cockpit geometry increases, the aerodynamic heating of the airframe surfaces also increases due to greater heat transfer surface areas which will induce more heat into the cockpit.

\subsection{Effect of Pilot Mean Skin Temperature and Cockpit WBGT on Engine Mass Flow Rates}

As stated by aero medical authorities that pilot will be in a state of thermal comfort when his/her mean skin temperature is $33^{\circ} \mathrm{C}$ [9]. Also as per the research study conducted by Institute of Aviation Medicine, RAAF [7] an upper limit of $28^{\circ} \mathrm{C}$ cockpit WBGT is necessary if physiological stress and impairment of performance of pilots are to be avoided. 


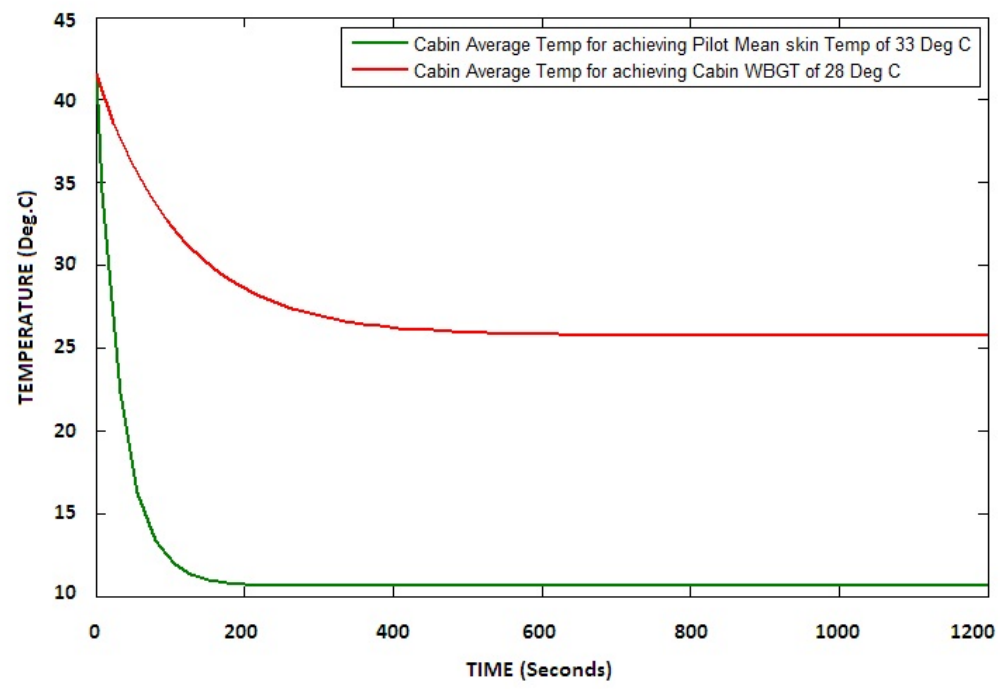

Fig 11. Effect on mass flow rate to achieve pilot mean skin temperature

In order to study the net effect on engine bleed flow rates to meet both the requirements of $28^{\circ} \mathrm{C}$ WBGT and a mean skin temperature of $33^{\circ} \mathrm{C}$, the parameters set for the cockpit cooling case analysis are considered. The mass flow rates supplied in both the cases include $0.092 \mathrm{~kg} / \mathrm{sec}$ and $0.32 \mathrm{~kg} / \mathrm{sec}$ respectively. From Fig 11 it can be seen that the cockpit average temperature is brought down from $26^{\circ} \mathrm{C}$ to $10.7^{\circ} \mathrm{C}$ to achieve the pilot mean skin temperature of $33^{\circ} \mathrm{C}$ for the specified flight operating condition. The mass flow rate requirement to effect this change in average temperature is approximately $0.32 \mathrm{~kg} / \mathrm{sec}$ at an air inlet temperature of $4^{\circ} \mathrm{C}$. However, a lower mass flow rate of $0.092 \mathrm{~kg} / \mathrm{sec}$ is required to achieve a cockpit WBGT of $28^{\circ} \mathrm{C}$. This implies that additional mass flow (i.e. 3.5 times) is to be bled from the engine compressor by to achieve the pilot mean skin temperature of $33^{\circ} \mathrm{C}$ resulting in the higher fuel consumption.

\subsection{Cockpit pressurization Requirements}

In order to analyze the cockpit pressurization requirements the following parameters are set during simulation. Altitude variation from sea level to $15 \mathrm{~km}$, aircraft climb rate $4920 \mathrm{ft} / \mathrm{min}$ and cockpit differential pressure of $34.5 \mathrm{kPa}$. The altitude and aircraft climb rate parameters are defined in a 1D look up table in a MATLAB/Simulink model block. The total time taken by aircraft to reach $15 \mathrm{~km}$ altitude is taken as 10 minutes from mean sea level reference [10].

At $15 \mathrm{~km}$ altitude the ambient pressure is approximately $12 \mathrm{kPa}$ which is one ninth the pressure at sea level. This reduced ambient pressure at altitudes poses a serious threat on health of the pilots. From fig 12 it can be seen that the cockpit pressure and ambient pressure are same up to $2.4 \mathrm{~km}$ altitude. The pressurization starts from $2.4 \mathrm{~km}$ onwards and up to an altitude of $7.0 \mathrm{~km}$ by maintaining the isobaric cockpit pressure of $75.2 \mathrm{kPa}$. 
Above $7.0 \mathrm{~km}$ altitude and up to an aircraft ceiling altitude of $15 \mathrm{~km}$ the cockpit pressure is gradually came down. At 15 $\mathrm{km}$ altitude the cockpit pressure is approximately $46.5 \mathrm{kPa}$. From Fig13 it can be seen that from mean sea level and up to an altitude of $2.4 \mathrm{~km}$ the differential pressure is zero as both ambient pressure and cockpit pressure are equal up to this altitude. From $2.4 \mathrm{~km}$ onwards and up to an altitude of $7.0 \mathrm{~km}$ the differential pressure gradually increases till it becomes $34.5 \mathrm{kPa}$. From $7 \mathrm{~km}$ onwards a constant differential pressure of $34.5 \mathrm{kPa}$ is maintained up to an aircraft ceiling altitude of $15 \mathrm{~km}$.

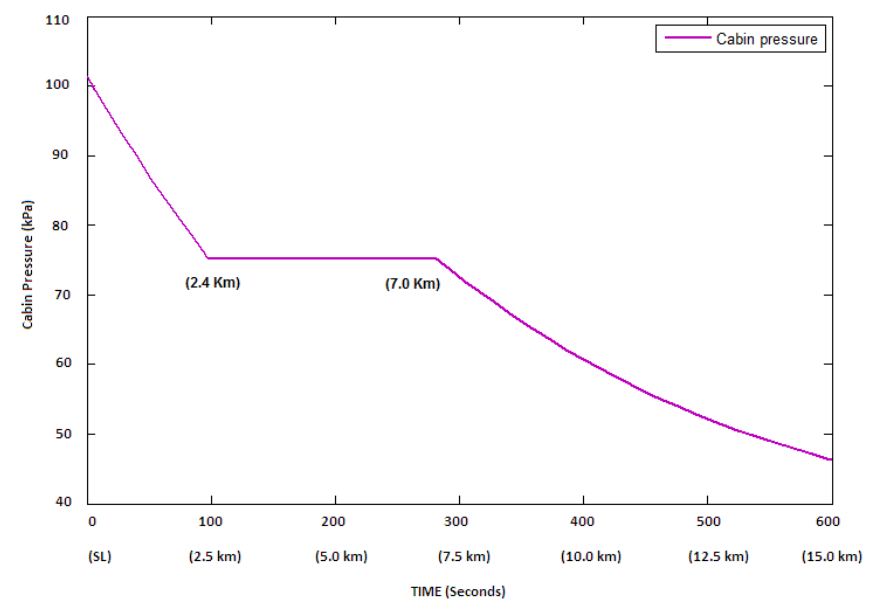

Fig 12. Cockpit Pressure v/s Altitude

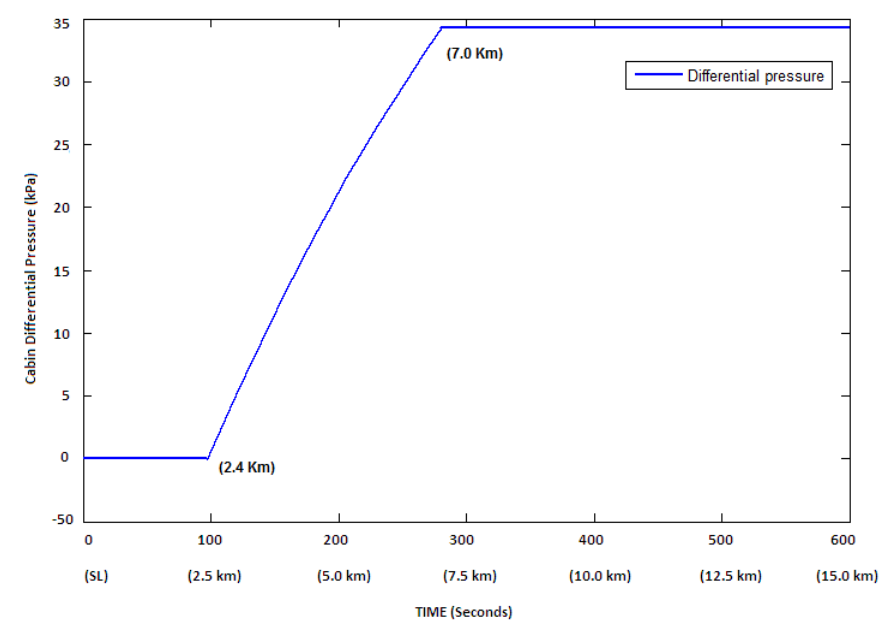

Fig 13. Cockpit Differential Pressure v/s Altitude

\section{Summary \& Conclusions}

The major components/equipments of the ECS for a typical military aircraft are modelled at system level with appropriate mathematical/governing equations. The various heat sources are identified and their net effect on cockpit thermal balance and corresponding impact on heat stress are simulated dynamically. In doing so a method for early stage ECS design at the system level is produced. Based on the simulation it is inferred that the heat sources are mainly dominated by the parameters like ambient temperatures, speed of the aircraft, altitudes, thermal mass and also the structural geometry of the 
cockpit including transparency areas. These heat sources will have a direct impact on cockpit thermal balance and also the heat stress levels on the pilots.

In order to avoid thermal stress of the pilots, the cockpit temperature and pressure are to be maintained at acceptable levels during the entire flight operating envelope. The mass flow rate and its inlet temperature play a significant role in achieving the same. In order to demonstrate the net effect on engine mass flow requirements for avoiding the heat stress on pilots, a case study analysis is carried out for a flight operating condition of 0.6 Mach at sea level with an ambient temperature of $45^{\circ} \mathrm{C}$. The analysis shows that, relatively a lower mass flow requirement of approximately $0.092 \mathrm{~kg} / \mathrm{sec}$ is sufficient to maintain the cockpit WBGT of $28^{\circ} \mathrm{C}$ at an air inlet temperature of $4^{\circ} \mathrm{C}$. However with the same mass flow rate, the pilot's mean skin temperature of $33^{\circ} \mathrm{C}$ cannot be achieved. It requires a mass flow requirement of approximately $0.32 \mathrm{~kg} / \mathrm{sec}$ at the same air inlet temperature so as to bring down the cockpit average temperature from $26^{\circ} \mathrm{C}$ to $10.7^{\circ} \mathrm{C}$. This demands an additional bleeding of the pressurized air from the engine compressor. Hence, it requires a trade-off between the level of heat stress to be maintained on pilots and a relative engine performance that is required to accomplish an intended mission requirements.

\section{Acknowledgments}

The authors would like to thank the management of Hindustan Aeronautics Limited, Aircraft Research and Design Centre, Bangalore, India, and Cranfield University, United Kingdom, for facilitating this study.

\section{References}

[1]. Michel, A.: "Air cycle Environmental Control System with fully energy regenerative high pressure water condensation and extraction”. WO99/02399 ed., B64D 13/06, United States (1999)

[2]. SAE Aerospace, “Applied Thermodynamics Manua”l. Characteristics of Equipment Components, Equipment Cooling System Design and Temperature Control System Design. AIR1168/6, Society of Automotive Engineers, USA (2004)

[3]. Tavares, S.: “Thermodynamic Study of Aircraft Air-conditioning Air Cycle Machines- 3 Wheel and 4 Wheel”. SAE Technical Paper Series, vol. 01-2579 E (2007)

[4]. "The Airliner Cabin Environment and the Health of Passengers and Crew". National Academy Press, Washington (2002)

[5]. HARDING, R.M., "Pressure changes and hypoxia”. Chapter 32, Medical aspects of harsh Environment, Department of aero medicine and neuroscience, Farnborough, United Kingdom (1996)

[6]. Keane, B.: “Method for Calculating Aircraft Heat Load”, Normaliar, NY (1178)

[7]. REBBECHI, B.: "Estimation of Cockpit Heat Loading in the Sea King Helicopter and Effectiveness of Possible Modifications to Improve Crew Thermal Environment”. AO 66096, Department of Defence, Aeronautical Research Laboratories, Melbourne, Australia (1977)

[8]. Lawson, C. P., AVD Lecture notes, School of Engineering. "Environmental Control Systems Requirements and Analysis”. Cranfield University. United Kingdom (2009) 
[9]. Hughes, T. L., “Cockpit Air Requirements for Crew Comfort in Military Aircraft”. C.P.No. 1094, Ministry of Technology, Aeronautical Research Council, Farnborough, London (1970)

[10]. Janardhana, S.: “Cabin heat loads modelling \& dynamic simulation of ECS of a single seater fighter aircraft”. (Master of Science thesis), Cranfield University, United Kingdom (2012) 
2015-01-30

Simulation for temperature control of a pÿmilitary aircraft cockpit to avoid pilot $s$ thermal stress

Shetty, Janardhana

Springer

Shetty J, Lawson C and Shahneh AZ., Simulation for temperature control of a military aircraft pÿcockpit to avoid pilot s thermal stress, CEAS Aeronautical Journal, Volume 6, Issue 2, pp.319-333 https://doi.org/10.1007/s13272-015-0149-0

Downloaded from Cranfield Library Services E-Repository 